\title{
Perancangan Software Defined Radar Untuk Radar Pulsa dan Radar FMCW
}

\author{
Octarina Nur Samijayani ${ }^{1}$, Suci Rahmatia ${ }^{1}$, Vita Nur Septiyani ${ }^{1}$, Ibrahim $^{1}$ \\ ${ }^{1}$ Teknik Elektro, Fakultas Sains dan Teknologi, Universitas Al Azhar Indonesia, \\ Komplek Masjid Agung Al Azhar Kebayoran Baru, Jakarta Selatan, 12110 \\ Penulis untuk Korespondensi/Email: octarina.nur@uai.ac.id
}

\begin{abstract}
Abstrak - Software Defined Radio (SDR) merupakan sistem komunikasi radio berbasis software yang saat ini mulai banyak diimplementasikan dan menunjukkan potensi yang besar. Tingginya efisiensi dalam hal biaya dibandingkan dengan sistem konvensional berbasis perangkat menjadi motivasi bagi berkembangnya konsep ini diberbagai aplikasi. Salah satu aplikasi yang dapat diterapkan menggunakan konsep SDR adalah sistem komunikasi Radar, Software Defined Radar (SDRadar). Radar berbasis software diharapkan dapat menurunkan biaya pembuatan hardware, serta dapat mendukung perancangan Radar yang dapat melakukan banyak fungsi dan lebih flexible untuk melakukan konfigurasi ulang. Radar multifungsi dapat dibangun dengan berbasis software yakni mulai dari pengaturan jenis sinyal, frekuensi operasi, hingga pada tahap pemrosesan sinyal radar. Penelitian ini merancang FMCW Radar menggunakan platform SDR. Simulasi dilakukan dengan mencoba posisi objek yang berbeda, dengan nilai SNR yang berbeda. Hasil simulasi menunjukkan implementasi konsep SDR untuk Radar dapat mendukung fleksibilitas rekonfigurasi parameter Radar. Untuk spesifik radar yang disimulasikan diperoleh bahwa SNR yang baik untuk dapat mendeteksi jarak object dengan baik (error <11\%) ialah diatas 20dB. Radar dengan SNR dibawah 20 dB tidak dapat mendeteksi jarak objek dengan baik, dimana error melebihi $50 \%$. Radar Pulsa disimulasikan menggunakan pernagkat USRP dengan factor pengkoreksi/kalibrasi 1.376, sedangkan untuk Radar FMCW masih terdapat error sebsar 70.8\%.
\end{abstract}

\section{Kata Kunci : SDR, SDRadar, FMCW Radar}

Absract - Software Defined Radio (SDR) is a software-based radio communication system that is currently implemented and show great potential to be developed. The efficiency in terms of cost as compared to conventional systems which based on devices is a motivation for the development of this concept in various applications. One of the applications that can be implemented utilizing the concept of SDR is Software Defined Radar (SDRadar). Radar with software based is expected to have lower cost and support the feasibility of Radar to perform in many functions and more flexible to be reconfigured. This research implement the FMCW Radar using SDR platform. Simulations carried out by trying different object positions, with different SNR values. The simulation results show the implementation concept of SDR's Radar can support the flexibility of Radar parameter reconfiguration. For specific simulated radar shows that a suitable SNR value to detect the distance of object (error $<11 \%$ ) is above $20 \mathrm{~dB}$. Radar with SNR under $20 \mathrm{~dB}$ could not detect the distance of objects well, where the error exceeds 50\%. Radar Pulse also simulated using USRP with factor correction or calibration factor of 1,376, while for FMCW with USRP still obtain high error of about $70.8 \%$.

Keywords: SDR, SDRadar, FMCW Radar. 


\section{PENDAHULUAN}

$\mathrm{R}$ adar di Indonesia saat ini masih banyak menghadapi tantangan baik dari segi teknologi perancangan maupun dalam hal pembiayaan produksi komponen Radar. Tidak banyak Radar yang dibuat oleh produsen dalam negeri. Radar di Indonesia masih banyak menggunakan perangkat buatan luar negeri/import dimana dari sisi harga tentunya terbilang cukup tinggi. Hal ini dikarenakan produsen lokal masih terkendala masalah biaya, baik biaya produksi komponen maupun biaya riset, uji coba, dan lain sebagainya.

Menilik pada kondisi geografis Indonesia, yang notabene merupakan kepulauan, diperlukan pengawasan terhadap lalu lintas baik udara maupun laut. Sehingga sebenarnya kebutuhan akan Radar di Indonesia cukup tinggi. Beberapa fungsi Radar seperti Radar tracking, searching dan remote sensing sangat diperlukan untuk pemantauan dan pelacakan jarak jauh.

Perkembangan konsep SDR saat ini menunjukkan potensi yang besar, terutama dalam menurunkan cost dari segi perangkat keras (hardware). Dengan menggunakan konsep ini perangkat keras dapat digantikan oleh software sehingga sangat mendukung untuk kemudahan rekonfigurasi parameter system Radar. Implementasi SDR pada bidang Radar saat ini di Indonesia merupakan hal yang terbilang baru. Saat ini masih berada pada tahap perancangan dan simulasi, belum pada tahap implementasi secara langsung. Namun beberapa penelitian menunjukkan hasil yang cukup menjanjikan. Penelitian ini mengimplementasikan konsep SDR pada sistem Radar, untuk menambah khasanah dalam penerapan konsep SDR, dan sebagai alternatif/metode lain untuk pengembangan teknologi Radar.

Teknologi Radar masih termasuk kurang digiatkan oleh engineer di Indonesia, hal ini seiring dengan tingginya biaya implementasi perangkat Radar. Diperlukan suatu teknologi yang dapat menjalankan fungsi Radar dengan biaya yang lebih murah. Teknologi berbasis Software Defined Radar merupakan salah satu solusi yang dapat dikembangkan untuk merancang Radar dengan biaya yang lebih murah, dan dapat didesain implementasi Radar yang memiliki beberapa fungsi dalam satu system. Penelitian ini bertujuan membuat rancangan sistem Radar berbasis Software Defined Radar (SDRadar), dimana bagian pemrosesan sinyal dan beberapa fungsi hardware digantikan oleh software. Penelitian mendesain sistem Radar yang dapat memiliki beberapa fungsi.

\section{KERANGKA TEORI}

Aplikasi Radar berkembang dari aplikasi militer kemudian saat ini banyak diimplementasikan untuk Air Traffic Control (ATC), Navigasi udrara, keamanan kapal laut dan pesawat, remote sensing, law enforcement serta dalam dunia kedokteran. Untuk aplikasi tertentu perlu didesain dan disesuaikan jenis sinyal dan jenis konfigurasi agar dapat memperoleh sinyal yang dapat membawa informasi yang lebih representatif.

Secara umum jenis Radar dibagi menjadi Radar Pulsa dan Radar FMCW. FMCW merupakan salah satu jenis radar dengan sinyal continous, dimana sinyal sinusoidal dimodulasi frekeunsi. Pada Radar FMCW, transmitter memancarkan gelomang radio dimana frequensi dari gelombang ini secara continue meningkat dan menurun dari suatu nilai frequensi referensi tertentu. Frequensi sinyal balikan yang diterima akan berbeda dari frekuensi yang diradiasikan. Perbedaan frekuensi merepresentasikan waktu yang diperlukan oleh sinyal untuk merambat dari transmitter sampai mengenai objek.

Pada bagian signal generation akan dirancang pembuatan sinyal FMCW, sedangkan pada pagian signal processing, akan dilakukan perhitungan nilai echoe signal yang diperoleh dari selisih antara frequensi yang diterima dengan frequensi yang dikirim. Adapun prinsip kerja FMCW dijelaskan pada Gambar 1.

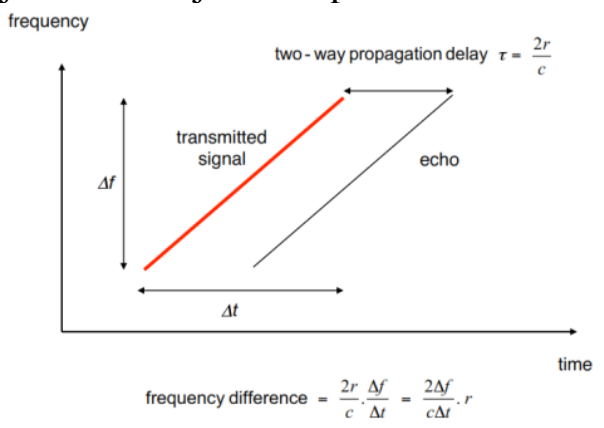

Gambar 1. Prinsip Kerja Radar FMCW [3] 
Perkembangan dunia Radar berbasis software yakni Software Defined-Radar menunjukkan potensi yang besar terutama dalam menurunkan cost pada pemrosesan sinyal. Penelitian dan pengembangan Radar berbasis SDR telah dimulai pada tahun 2007, yakni untuk aplikasi otomotif, bekerja pada frekuensi $24 \mathrm{GHz}$ [4]. Peluang besarnya pengembangan sistem Software Defined Radar menggunakan perangkat USRP direview pada [5]. Pada paper ini dibahas SDRadar untuk aplikasi target tracking.

FMCW Radar untuk aplikasi pemantauan cuaca dengan menggunakan GNU Radio telah disimulasikan pada [6]. Prorotipe radar yang dibuat bekerja pada frequensi $2.1 \mathrm{GHz}$ (S-band). Radar ini mampu membedakan tiga objek yang dideteksi. FMCW banyak digunakan pada frequency P, X, C, dan L band. Untuk aplikasi frequency tinggi FMCW dapat digunakan untuk mendeteksi objek yang berukuran kecil dan bergerak, sehingga banyak digunakan untuk aplikasi pemantau cuaca.

Pembahasan mengenai keunggulan implementasi Radar menggunakan teknologi Software Defined Radio (SDR) yaitu dapat menghasilkan prototipe radar yang fleksibel dan low-cost untuk aplikasi Ground Penetrating Radar (GPR) [7]. Dengan menggunakan konsep SDR, Radar dapat lebih bersifat flexibel dalam pemrosesan sinyal, yaitu signal encoding, decoding dan processing.

Penelitian terkini pada tahun 2015, telah dikembangkan Cognitive Radar untuk pelacakan objek (target tracking) berbasis SDR [8]. Cognitive Radar yang dirancang menggunakan metode Maximum a Posteriori Penalty Function (MAP-PF), dimana secara kognitif mengendalikan bagian sensor dan pemrosesan. Sistem Radar yang dibangun menggunakan jenir Radar Pulsa dimana nilai (Pulse Repetition Frequency) PRF perlu diadjust untuk mengoptimasi kinerja pelacakan. Dengan memanfaatkan konsep SDR, beberapa parameter sistem dapat diadjust, dan diubahubah dengan mudah tanpa harus merubah dari perangkat keras atau komponennya.

\section{METODE PENELITIAN}

Sistem Radar yang dirancang pada penelitian ini memanfaatkan teknologi SDR. Jenis Radar yang diimplementasikan adalah FMCW Radar. Adapun jenis sinyal FMCW adalah bentuk sinyal continuous yang termodulasi FM. Sinyal ini di bangkitkan pada periode waktu tertentu yang disebut Pulse Repetirion Period (PRT). Berbeda dengan Pulse Radar, satu periode sinyal FMCW ialah berupa sinyal continuous dengan modulasi frequency, dimana dalam satu periode dihasilkan sinyal dengan frequency yang semakin meningkat. Penelitian ini mensimulasikan sistem Radar FMCW dengan konfigurasi monostatik dan bistatik. Simulasi pertama menggunakan konfigurasi monostatik, yakni transmitter dan receiver berada pada lokasi yang sama.

Untuk simulasi FMCW generation pada tahap I ini, diinisiasi dengan nilai spesifikasi yang ditunjukkan pada Tabel 1. Untuk selanjutnya untuk menganalisa parameter yang dapat bekerja pada USRP yang tersedia dilakukan penyesuaian nilai parameter Radar. Spesifikasi radar FMCW yang disimulasikan adalah sebagai berikut:

Tabel 1. Spesifikasi FMCW Radar

\begin{tabular}{cll}
\hline No. & \multicolumn{1}{c}{ Parameter } & \multicolumn{1}{c}{ Nilai } \\
\hline 1 & Frequensi kerja & $1 \mathrm{MHz}-5 \mathrm{MHz}$ \\
2 & Chirp Freq & $0-10 \mathrm{kHz}$ \\
3 & Chirp Waveform & Sawtooth, Triangle \\
4 & Chirp Period & $1 \mathrm{~ms}-4 \mathrm{~ms}$ \\
5 & Sampling Rate & $6 \mathrm{MS} / \mathrm{s}$ \\
\hline
\end{tabular}

Perancangan sistem Radar terdiri dari perancangan software dan perancangan hardware. Tahap perancangan software terdiri dari dua tahap besar, yakni Signal Generation (Pembangkitan Sinyal) dan Signal Processing (Pemrosesan Sinyal).

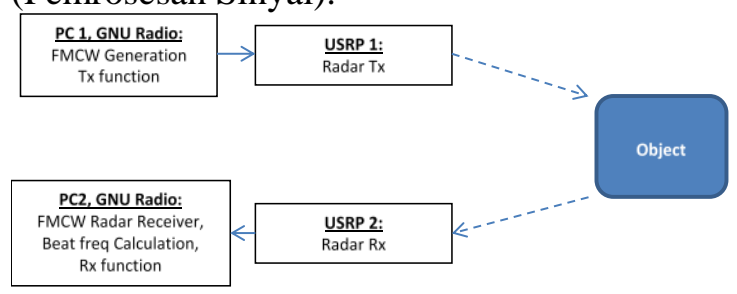

Gambar 2. Perancangan Perangkat Sistem Radar 


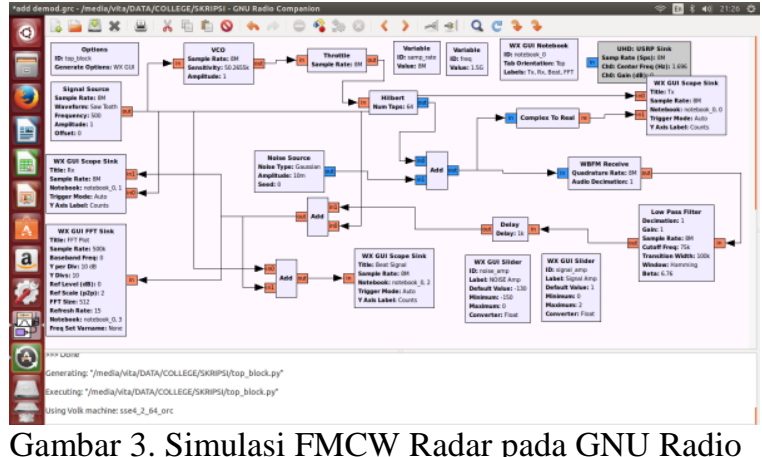

\section{HASIL DAN PEMBAHASAN}

Selanjutnya uji coba rekonfigurasi parameter nilai PRF ditunjukkan pada Gambar berikut. Pada penelitian ini disimulasikan FMCW Radar dengan nilai PRF yang berbeda beda, yakni $250 \mathrm{~Hz}, 500 \mathrm{~Hz}$, dan $1000 \mathrm{~Hz}$. Perubahan nilai PRF akan mempengaruhi jarak unambiguity terjauh yang dapat dideteksi oleh Radar. Semakin tinggi frekuensi PRF akan membuat jarak jangkauan unambiguity Radar semakin kecil.

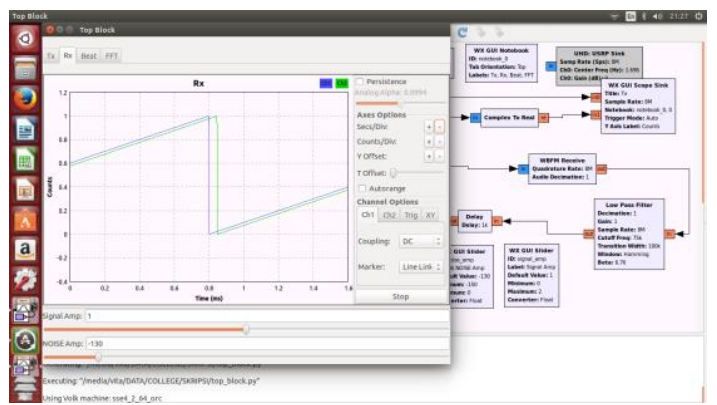

Gambar 4. Perbandingan Tx signal dengan Rx signal (Time vs Frequency)

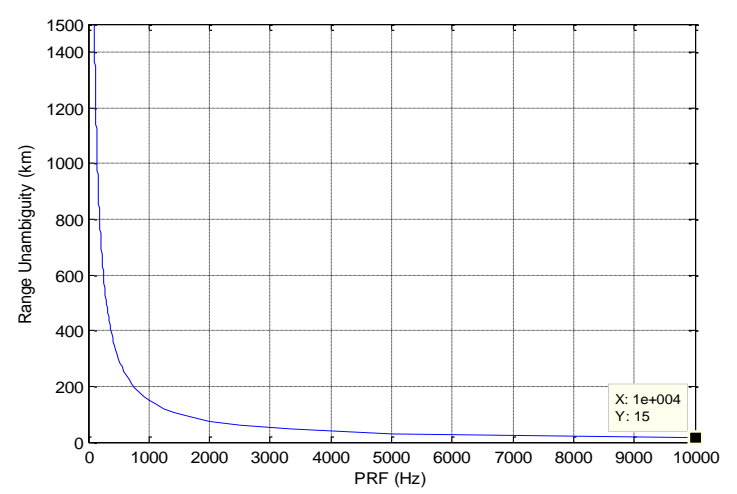

Gambar 5. Perubahan PRF Radar terhadap Unambiguity Range

Uji coba selanjutnya adalah uji coba Radar mendeteksi object. Pada tahap simulasi ini, keberadaan object ditandai dengan adanya delay dari received signal. Pada simulasi ini object berada pada jarak $15 \mathrm{~km}$. Uji coba dilakukan dengan SNR yang berbeda.

(a)
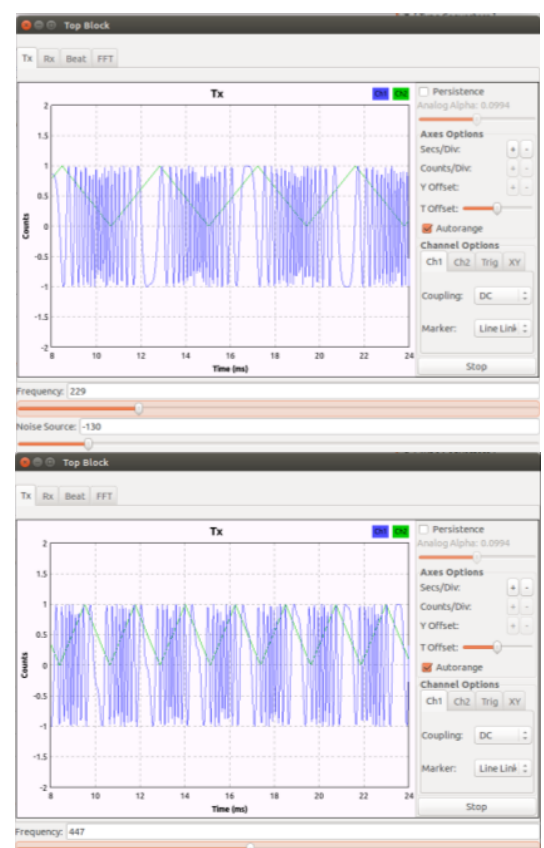

(b)
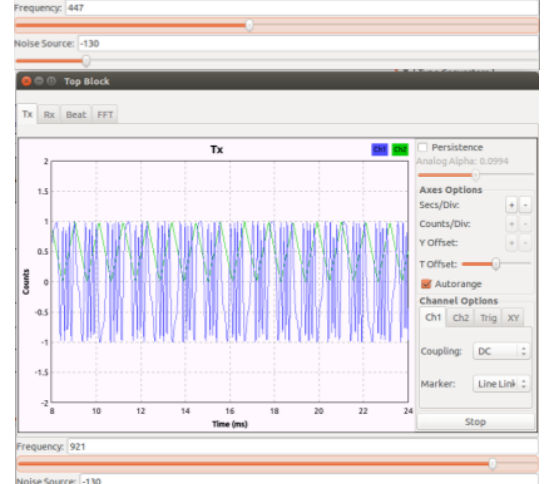

(c)

Gambar 6. Uji coba rekonfigurasi PRF $(\mathrm{PRF}=250$

$\mathrm{Hz}, \mathrm{PRF}=500 \mathrm{~Hz}, \mathrm{PRF}=10 \mathrm{kHz})$

Berikut jarak unambiguity yang diperoleh dengan nilai PRF $250 \mathrm{~Hz}, 500 \mathrm{~Hz}$, dan 1000 $\mathrm{Hz}$.

Tabel 2. Range unambiguity dengan PRF yang berbeda

\begin{tabular}{cc}
\hline PRF & Unambiguity Range \\
\hline $250 \mathrm{~Hz}$ & $600 \mathrm{~km}$ \\
$500 \mathrm{~Hz}$ & $300 \mathrm{~km}$ \\
$1000 \mathrm{~Hz}$ & $150 \mathrm{~km}$ \\
\hline
\end{tabular}


Tabel.3. Pengukuran Jarak Objek dengan SNR yang berbeda

\begin{tabular}{c|c|c|c|c}
\hline $\begin{array}{c}\text { SNR } \\
(\mathbf{d B})\end{array}$ & $\begin{array}{c}\text { Measured } \\
\mathbf{f}_{\text {beat }} \\
(\mathbf{M H z})\end{array}$ & $\begin{array}{c}\text { Measured } \\
\text { Range } \\
(\mathbf{k m})\end{array}$ & $\begin{array}{c}\text { Actual } \\
\text { Range } \\
(\mathbf{k m})\end{array}$ & $\begin{array}{c}\text { Error } \\
\%\end{array}$ \\
\hline 100 & 0.1800 & 13.50 & 15 & 9.99 \\
\hline 40 & 0.1797 & 13.47 & 15 & 10.17 \\
\hline 30 & 0.1805 & 13.54 & 15 & 9.73 \\
\hline 20 & 0.1898 & 14.23 & 15 & 5.12 \\
\hline 10 & 0.3060 & 22.95 & 15 & 53.0 \\
\hline 5 & 0.4720 & 35.40 & 15 & 136.01 \\
\hline 1 & 0.7455 & 55.91 & 15 & 272.77 \\
\hline
\end{tabular}

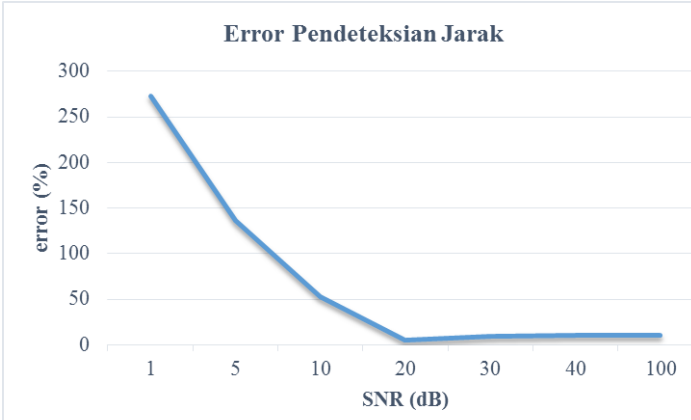

Gambar 7. Hasil pendeteksian jarak dengan SNR yang berbeda

Dari hasil percobaan deteksi object dengan SNR yang berbeda, untuk spesifik radar yang disimulasikan diperoleh bahwa SNR yang baik untuk dapat mendeeksi jarak object dengan baik (error $<11 \%$ ) ialah dibawah $20 \mathrm{~dB}$. Radar dengan SNR diatas $20 \mathrm{~dB}$ tidak dapat mendeteksi jarak objek dengan baik, dimana error melebihi $50 \%$.

Implementasi SDRadar pada hardware menggunakan USRP B200 sebagai transmitter dan receiver, GNU Radio untuk mengenerate sinyal dan menerima sinyal yang terpantul dari object, serta antena. Berikut Setup implementasi SDRadar.

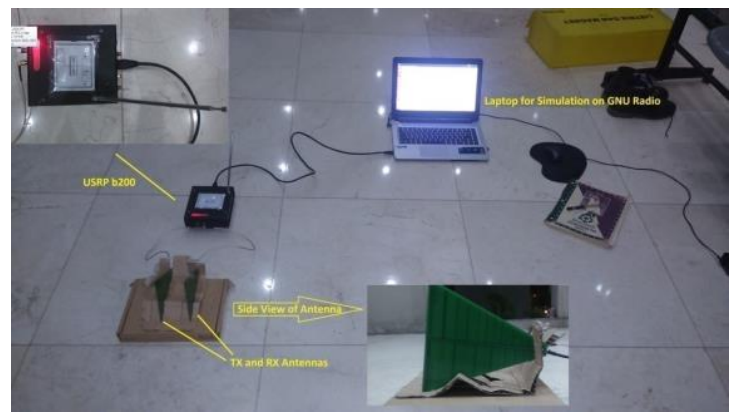

Gambar 8. Set up Implementasi SDRadar pada USRP
Tabel 4. Range detection untuk Radar FMCW

\begin{tabular}{ccccc}
\hline $\begin{array}{c}\text { Real } \\
\text { Range } \\
(\mathrm{m})\end{array}$ & $\begin{array}{c}\text { Delta } \\
\text { time } \\
(\mathrm{ms})\end{array}$ & $\begin{array}{c}\text { Range } \\
\text { calculation } \\
(\mathrm{km})\end{array}$ & $\begin{array}{c}\text { Delta } \\
\text { range } \\
(\mathrm{m})\end{array}$ & $\begin{array}{c}\text { Error } \\
(\%)\end{array}$ \\
\hline 10 & 0.7 & 105 & 95 & $90,5 \%$ \\
10 & 0.6 & 90 & 80 & $88.8 \%$ \\
10 & 0.1 & 15 & 5 & $33.3 \%$ \\
\hline \multicolumn{4}{c}{ Average error: } & $70.8 \%$ \\
\hline
\end{tabular}

Hasil uji coba Radar FMCW untuk jarak dekat, masih terdapat error yang sangat besar $70.8 \%$. Beberapa percobaan juga masih gagal menerima sinyal receive. Pada implementasi FMCW Radar, pengkondisian ruang untuk experiment perlu disesuaikan dengan parameter Radar. Untuk real parameter Radar biasanya adalah untuk mendeteksi objek dengan jarak jauh, diatas $100 \mathrm{~m}$, namun pada skala pengujian tidak dapat dilakukan pengujian untuk jarak tersebut. Untuk deteksi objek dari jarak sangat dekat, sinyal echo dari object juga sangat kecil, sehingga cukup sulit untuk mengekstrak informasi delaynya.

\section{KESIMPULAN}

Radar berbasis Software Defined Radar (SDR) telah disimulasikan pada software dan eksperimen real transmission dengan menggunakan perangkat keras USRP. Implementasi SDRadar diuji coba untuk simulasi Radar Pulsa dan Radar FMCW. Pada penelitian ini telah disimulasikan pengaturan frequency dan bentuk waveform sinyal Radar yang ditransmisikan. Simulasi dilakukan dengan mencoba posisi objek yang berbeda, dengan nilai SNR yang berbeda. Untuk spesifik radar yang disimulasikan diperoleh bahwa SNR yang baik untuk dapat mendeteksi jarak object dengan baik (error <11\%) ialah diatas $20 \mathrm{~dB}$. Radar dengan SNR dibawah $20 \mathrm{~dB}$ tidak dapat mendeteksi jarak objek dengan baik, dimana error melebihi 50\%. Radar Pulsa disimulasikan menggunakan pernagkat USRP dengan factor pengkoreksi/kalibrasi 1.376 , sedangkan untuk Radar FMCW masih terdapat error sebsar $70.8 \%$.

Dapat disimpulkan bahwa dengan menggunakan konsep SDRadar ini dapat mereduksi biaya perangkat signal generator dan lebih mendukung interkoneksi hasil deteksi sinyal dengan proses pengolahan sinyal selanjutnya yang berbasis software. Rancangan 
SDRadar FMCW yang disimulasikan menunjukkan keunggulan metode berbasis software ini yakni dimana pengaturan parameter Radar dapat dilakukan pada layer software saja tanpa perlu mengganti para layer perangkat kerasnya.

\section{UCAPAN TERIMA KASIH}

Penelitian ini terlaksana atas dukungan dari LP2M Universitas Al Azhar Indonesia, dan Laboratorium Teknik Elektro Fakultas Sains dan Teknologi, Universitas Al Azhar Indonesia.

\section{DAFTAR PUSTAKA}

[1]. Merill Skolnik. Radar Handbook. McGrawHill, 3th Edition. 2008.

[2]. Radar Principle, http://www.radartutorial.eu/01.basics/Ra dar\%20Principle.en.html

[3]. Thibault Debatty, Software Defined RADAR a State of the Art, 2nd International Workshop on Cognitive Information Processing, 2010.
[4]. 24GHz Software-Defined Radar System for Automotive Applications. Proceedings of the 10th European Conference on Wireless Technology, 2007.

[5]. Sandra Costanzo, Francesco Spadafora, Potentialities of USRP-Based Software Defined Radar Systems, Progress In Electromagnetics Research B, Vol. 53, 417-435, 2013.

[6]. Aditya Prabaswara, Achmad Munir, Andriyan B. Suksmono. GNU Radio Based Software-Defined FMCW Radar for Weather Surveillance Application. 6th International Conference on Telecommunication Systems, Services, and Applications, 2011.

[7]. Ralston, J, Software defined radar: An open source platform for prototype GPR development. Ground Penetrating Radar (GPR) 14th International Conference, 2012.

[8]. Bell, K.L., Cognitive radar for target tracking using a software defined radar system, Radar Conference (RadarCon), 2015 IEEE, 2015. 